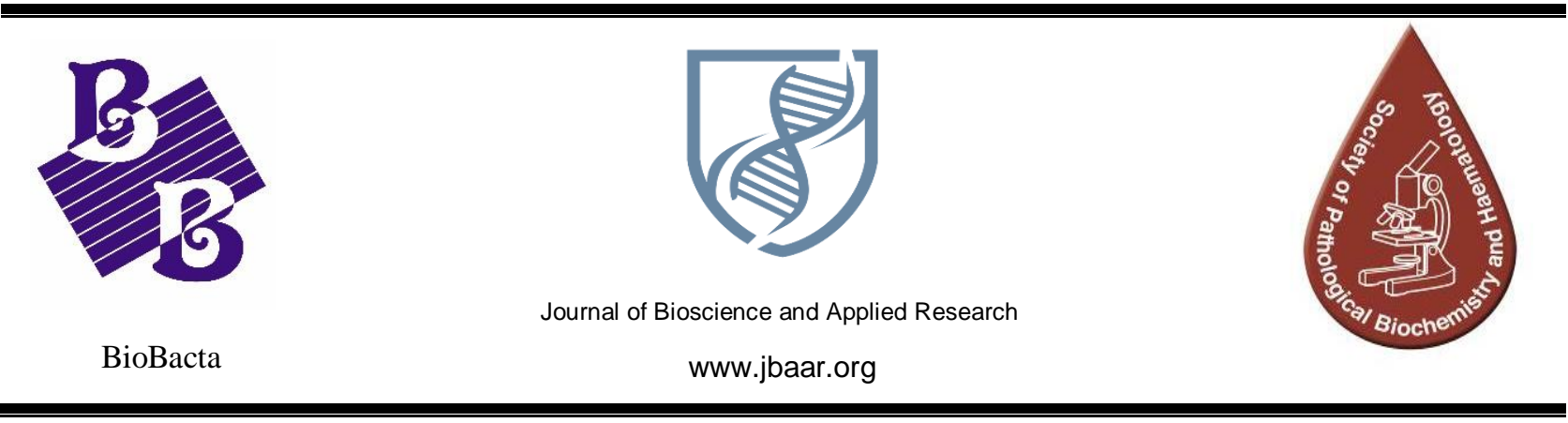

\title{
Annona muricata Attenuates Cadmium-Induced Oxidative Stress and Renal Toxicity in Wistar Rats
}

\section{Johnson Olaleye Oladele $^{1,3}$, Olu Israel Oyewole ${ }^{1 *}$, Moses Oyedotun Oyeleke ${ }^{3}$, Omowumi Oyeronke Adewale ${ }^{2}$, and Oluwamuyiwa Emmanuel Adeloju ${ }^{1}$}

${ }^{1}$ Phytomedicine and Toxicology Laboratories, Department of Biochemistry, Faculty of Basic and Applied Sciences, Osun State University, Osogbo, Nigeria.

${ }^{2}$ Cancer Research and Molecular Toxicology Laboratories, Department of Biochemistry, Faculty of Basic and Applied Sciences, Osun State University, Osogbo, Nigeria

${ }^{3}$ Biochemistry Unit, Department of Chemical Sciences, Faculty of Sciences,

Kings University, Ode-Omu, Nigeria.

*Corresponding author. E-mail: $\underline{\text { ioluoye@yahoo.com }}$

\begin{abstract}
Cadmium is a known industrial toxicant that accumulates in the kidney and causes oxidative damage. The present study was carried out to evaluate the attenuating effects of Annona muricata seed extracts against cadmium mediated renal toxicity in Wistar rats. Twenty-eight (28) Wistar albino rats sorted into four groups of seven rats per group were used in this study. Group A serves as the control and received distilled water orally. Group B, C, and D were administered $5 \mathrm{mg} / \mathrm{kg}$ body weight cadmium chloride with Group C and D were treated daily with 200 and $500 \mathrm{mg} / \mathrm{kg}$ body weight of ethanolic seed extract of Annona muricata (ESEAM) respectively by oral administration while group B was left untreated for 14 days. Results obtained showed that cadmium significantly $(\mathrm{P}<0.05)$ increased the serum level of urea and creatinine. Oxidative stress was induced by cadmium with a significant increase in MDA level and decrease concentration in ascorbic acid, GSH, GPx, SOD and CAT in the kidney. Efficacy of Annona muricata seed extracts against renal toxicity was evaluated in terms of biochemical estimation of enzymatic and non-enzymatic antioxidant activities, histopathological changes, and rate of lipid peroxidation. Treatment with ESEAM prevented deteriorative effects induced by $\mathrm{Cd}$ through a protective mechanism that involved the reduction of increased oxidative stress.
\end{abstract}

Keywords: Annona muricata, cadmium chloride, oxidative damage, lipid peroxidation, renal dsyfunction 


\section{INTRODUCTION}

Cadmium $(\mathrm{Cd})$ is a soft, bluish-white divalent metal and a well-known industrial toxicant which accumulates in the kidney and cause oxidative damage. The most common sources of cadmium toxicity are foods such as rice and wheat which are grown in soil contaminated by sewage sludge, superphosphate fertilizers, and irrigation water. Nogawa et al. reported the toxicity effects of $\mathrm{Cd}$ on some members of a local agricultural community who accidentally consume cd contaminated rice developed Itai-Itai disease and renal abnormalities, including proteinuria and glucosuria (Nogawa et al., 2004). After the intake and reabsorption, $C d$ enters the blood where it binds to the red blood cell (RBC) membranes and plasma albumin. Oyewole et al. have documented that exposure to cadmium in the form of cadmium chloride induced hyperlipidemia and pancytopenia in rats (Oyewole et al., 2016). Cd also induced oxidative stress, nephrotoxicity and hepatotoxicity in rats (Oyewole and Akinbamijo, 2015). Its carcinogenic effects have also been documented (Sorahan and Lancashire, 1997).

Natural products such as phytochemicals that are derived from plants have been used to help mankind sustain its health before the exploration of western medicine. Over many decades, the phytochemicals in plants have been a major template for pharmaceutical discovery. The importance of the active ingredients of plants in agriculture and medicine has stimulated significant scientific interest in the biological activities of these substances (Moghadamtousi et al., 2014). Plants with a long history of usage in traditional medicine are a rich sources of active phytoconstituents that provide medicinal or health benefits against various ailments and diseases. One such plant with extensive traditional use is Annona muricata whose fruit is commonly known as soursop. It is a member of the Annonaceae family comprising approximately 130 genera and 2300 species (Mishra et al., 2013).

Locally, Annona muricata fruit is used as natural medicine for arthritic pain, neuralgia, arthritis, diarrhea, dysentery, fever, malaria, parasites, rheumatism, skin rashes, and worms, and it is also eaten to elevate a mother's milk after childbirth while its leaves are employed to treat cystitis, diabetes, headaches and insomnia (Mishra et al., 2013; Adewole and Caxton-Martins, 2006; De Souza et al., 2009). The crushed seeds are believed to have antihelminthic activities against external and internal worms and parasites. In South America and tropical Africa, including Nigeria, leaves of A. muricata are deployed as an ethnomedicine against tumors and cancer (Adewole and Ojewole, 2009). Antiinflammatory, hypoglycemic, sedative, smooth muscle relaxant, hypotensive and antispasmodic properties have also been attributed to the leaves, barks, and roots of A. muricata (Mishra et al., 2013). In addition to ethnomedicinal uses, the fruits are widely employed for the preparation of beverages, candy, ice creams, shakes and syrups (Wu et al., 1995).

Based on this background, this study was therefore designed to assess the renal protective ability of ethanolic seed extract of Annona muricata (ESEAM) against cadmium mediated renal toxicity in Wistar rats.

\section{MATERIALS AND METHODS}

\section{Chemicals/Reagents}

Creatinine and urea kits are products of Randox Laboratories, United Kingdom. Cadmium chloride, ethanol, chloroform, and $\mathrm{KCl}$ are products of $\mathrm{BDH}$ Poole England. Antioxidant kits were purchased from Sigma Aldrich Company St Louis USA.

\section{Collection of Plant Material and Preparation of Extract}

Annona muricata seeds were collected at Osogbo Osun State, Nigeria. The seeds were air-dried to a constant weight at room temperature. The dried seeds were grinded into powdery form with the Diki blender machine. The powdered seeds were stored in an air-tight polythene bag until use. $500 \mathrm{~g}$ of the powdered sample was dissolved in 3.0 Litre $(1: 6 \mathrm{w} /$ v) of $98 \%$ absolute ethanol to extract the phytochemicals present in the seed sample. The soaking was done for 72 hours after which the extract 
was filtered using a white muslin cloth. The mixture was concentrated by rotary evaporator at $80^{\circ} \mathrm{c}$. The concentrated extract was obtained by the total removal of ethanol in the water bath. The obtained crude extract was weighed and used to prepare the stock solution for administration.

\section{Experimental animals}

Twenty-eight (28) Wistar strain albino rats of weight 140-150 g were used for this study. They were obtained and raised at the Central Animal House, Osun State University, Osogbo, Nigeria. Rats were kept under laboratory conditions $\left(25 \pm 2{ }^{\circ} \mathrm{C}\right)$ and relative humidity of $50 \pm 15 \%$ ) in cages cleaned of metabolic waste twice daily and were allowed to acclimatize for two weeks. They were exposed to 12 hours of daylight and darkness, fed with rat pellet and water ad libitum. The experiment was carried out in accordance with current rules and guidelines that have been established for the care of laboratory animals (National Research Council, 2011). The rats were acclimatized for two weeks before treatment commenced.

\section{Animal grouping and administration}

The rats were divided randomly into four (4) groups (A-D) of seven (7) animals per group. The mean weight for each group was determined and recorded. $5 \mathrm{mg} / \mathrm{kg}$ bw of Cadmium Chloride was used in this study based on the previous method of Oyewole et $a l$., 2016. The ethanolic seed extract of Annona muricata (ESAM) was administered every $24 \mathrm{hrs}$ and cadmium was administered every $72 \mathrm{hrs}$ on a total of 14 days administration.

Group A- Normal control rats received distilled water.

Group B- Positive control rats received $5 \mathrm{mg} / \mathrm{kg}$ bw of Cadmium chloride.

Group C- Rats received $5 \mathrm{mg} / \mathrm{kg}$ bw of Cadmium chloride $+200 \mathrm{mg} / \mathrm{kg}$ bw ESAM.

Group D- Rats received $5 \mathrm{mg} / \mathrm{kg}$ bw of Cadmium chloride $+500 \mathrm{mg} / \mathrm{kg}$ bw ESAM.

\section{Preparation of Serum}

The rats were sacrificed $24 \mathrm{hrs}$ of the last treatment by cervical dislocation and blood sample collected into a clean, dry centrifuge tube. The blood was left for $10 \mathrm{~min}$ at room temperature to clot after which it was centrifuged at 4,000 rpm in an MSC (Essex, UK) bench centrifuge. The clear supernatant (serum) was aspirated using a Pasteur pipette into clean, dry sample bottles and then stored at $4{ }^{\circ} \mathrm{C}$ for biochemical analyses.

\section{Preparation of homogenates}

The kidneys were quickly excised from the rat and immediately placed on a blotting paper to remove blood stains. It was then rinsed in $1.15 \% \mathrm{KCl}$ to remove haemoglobin followed by homogenization in 4 volumes of ice-cold $0.01 \mathrm{M}$ potassium phosphate buffer, (pH 7.4) using the Teflon homogenizer. The homogenate was centrifuged at $12,500 \mathrm{~g}$ for 20 minutes at $4{ }^{\circ} \mathrm{C}$ to obtain supernatants (postmitochondrial fractions) which were stored till required for the assay.

\section{Determination of Biochemical Parameters}

The level of SOD activity in the kidney was determined by the method of Mistra and Fridovich, 1972. Catalase activity was determined according to the method of Sinha, 1972. The method of Jollow et al. was used in estimating the level of reduced glutathione (GSH) (Jollow et al., 1974). GPx activity was determined according to the method of Rotruck et al., 1973). Lipid peroxidation (malondialdehyde) was assayed by using the procedure of Vashney and Kale, 1990. The ascorbic acid concentration was determined according to the method of Jagota and Dani, 1982. Serum creatinine and urea were determined colorimetrically as earlier described Cheesbrough, 2005.

\section{Statistical analysis}

Data of results were expressed as mean \pm SD. The comparison was done using a one-way analysis of variance (ANOVA) between the control and treatment groups. $\mathrm{P}$ values $<0.05$ were considered statistically significant.

\section{RESULTS}

Effects of ESEAM on the body weight gain and relative kidney weight of rats exposed to cadmium 
Treatment of rats with cadmium resulted in $500 \mathrm{mg} / \mathrm{kg}$ body weight significantly increased these significant decrease in body weight gain and relative the body weight gain even higher than the control kidney weight when compared with the control, while it produced no significant difference in the however, treatment with ESEAM at 200 and relative kidney weight at the two doses (table 1).

Table 1: Body weight gain and relative kidney weight of rats administered cadmium and ethanolic seed extract of Annona muricata

\begin{tabular}{|c|c|c|}
\hline Experimental groups & Body weight gain (g) & Relative kidney weight (\%) \\
\hline Group A & $12.55 \pm 2.39$ & $0.69 \pm 0.09$ \\
Group B & $10.00 \pm 3.23^{*}$ & $0.58 \pm 0.09 *$ \\
Group C & $15.20 \pm 5.02^{* *}$ & $0.62 \pm 0.04$ \\
Group D & $15.00 \pm 2.10^{* *}$ & $0.63 \pm 0.32$ \\
\hline
\end{tabular}

Values are mean of 6 rats \pm SD. *Significantly lower than the control at $p<0.05$.

$* *$ Significantly higher than the control at $\mathrm{p}<0.05$.

Key: A=Control. $\mathrm{B}=\mathrm{Cd}$ only. $\mathrm{C}=\mathrm{Cd}+200 \mathrm{mg} / \mathrm{kg}$ bw ESEAM. $\mathrm{D}=\mathrm{Cd}+500 \mathrm{mg} / \mathrm{kg}$ bw ESEAM

Effects of ESEAM on lipid peroxidation level in the kidney of rats exposed to cadmium

Results revealed that cadmium caused a significant increase in MDA level when compared with the control indicating induction lipid peroxidation.
However, treatment with ESEAM at 200 and $500 \mathrm{mg} / \mathrm{kg}$ body weight significantly reduced the induced lipid peroxidation in a dose-dependent manner (fig 1).

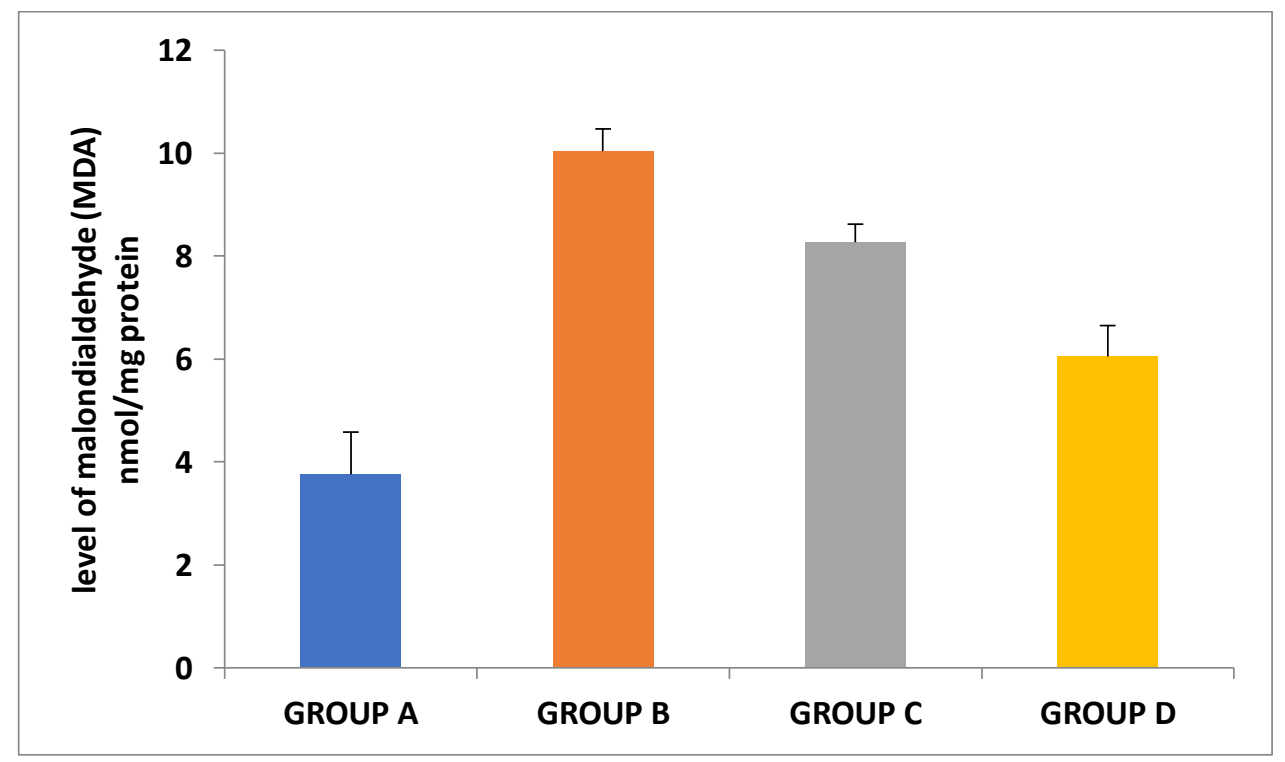

Figure 1: Lipid peroxidation (MDA level) in the kidney of cadmium-intoxicated rats treated with Annona nuricata seed extract

Key: A=Control. $\mathrm{B}=\mathrm{Cd}$ only. $\mathrm{C}=\mathrm{Cd}+200 \mathrm{mg} / \mathrm{kg}$ bw ESEAM. $\mathrm{D}=\mathrm{Cd}+500 \mathrm{mg} / \mathrm{kg}$ bw ESEAM 
Effects of ESEAM on GSH an in the kidney and ascorbic acid concentrations in the kidney of rats exposed to cadmium

Cadmium caused a significant decrease in both GSH and ascorbic acid concentrations when compared with the control, co-administration with ESEAM at 200 and $500 \mathrm{mg} / \mathrm{kg}$ body weight resulted in a significant moderation of these molecules in a dosedependent manner (fig 2).

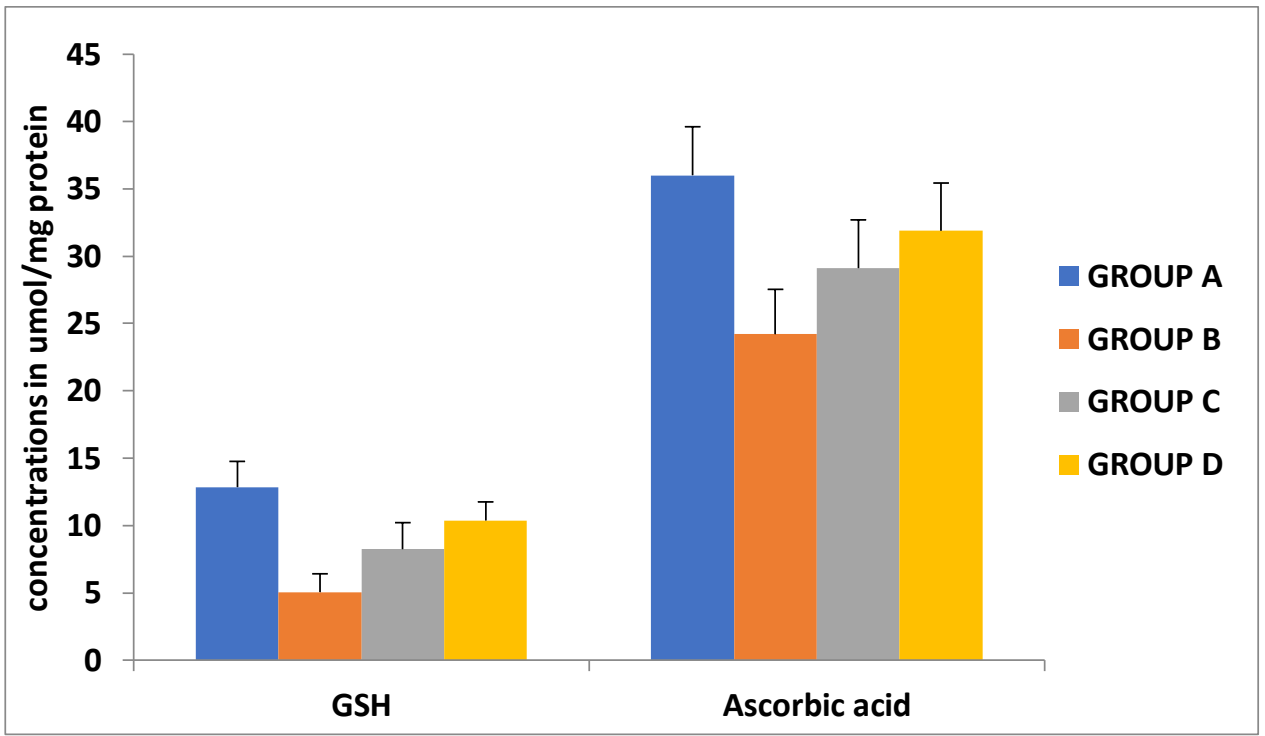

Figure 2: Reduced glutathione and ascorbic acid content in the kidney of cadmium-intoxicated rats treated with Annona nuricata seed extract

Key: $\mathrm{A}=$ Control. $\mathrm{B}=\mathrm{Cd}$ only. $\mathrm{C}=\mathrm{Cd}+200 \mathrm{mg} / \mathrm{kg}$ bw ESEAM. $\mathrm{D}=\mathrm{Cd}+500 \mathrm{mg} / \mathrm{kg}$ bw ESEAM

Effects of ESEAM on catalase, SOD, and GPx in the kidney of rats exposed to cadmium

Exposure of rats to cadmium at the reported dose resulted in a significant decrease in the activities of catalase, SOD, and GPx when compared with the control indicating increased generation of oxidative stress. Co-administration with ESEAM at 200 and $500 \mathrm{mg} / \mathrm{kg}$ body weight was able to abrogate these conditions (fig 3).

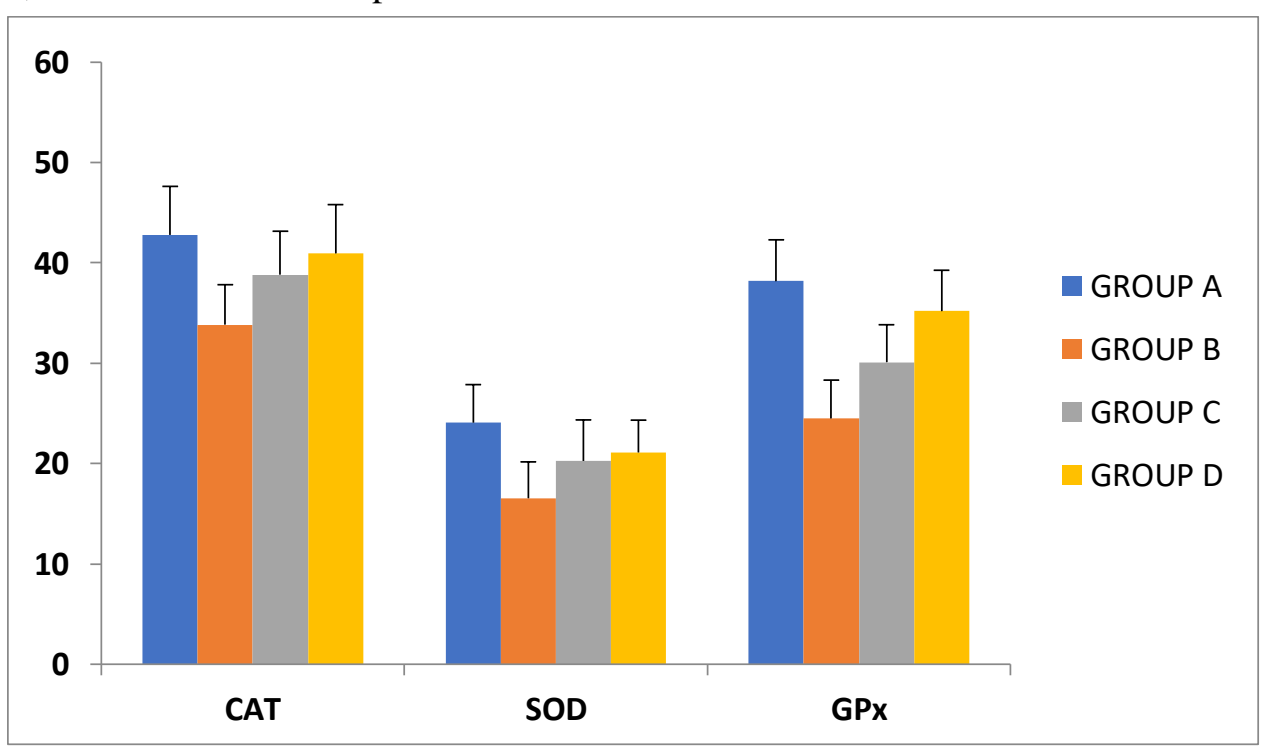

Figure 3: Catalase (CAT), superoxide dismutase (SOD) and glutathione peroxidase (GPx) content in the kidney of cadmium-intoxicated rats treated with Annona nuricata seed extract

Key: A=Control. $\mathrm{B}=\mathrm{Cd}$ only. $\mathrm{C}=\mathrm{Cd}+200 \mathrm{mg} / \mathrm{kg}$ bw ESEAM. $\mathrm{D}=\mathrm{Cd}+500 \mathrm{mg} / \mathrm{kg}$ bw ESEAM 
Effects of ESEAM on kidney function

biomarkers in the serum of rats exposed to cadmium

Cadmium caused a significant increase in the concentrations of urea and creatinine when compared with the control signifying a compromised kidney function. However, the presence of ESEAM at 200 and $500 \mathrm{mg} / \mathrm{kg}$ body weight cadmium-induced rats resulted in significant amelioration of this condition (fig 4).

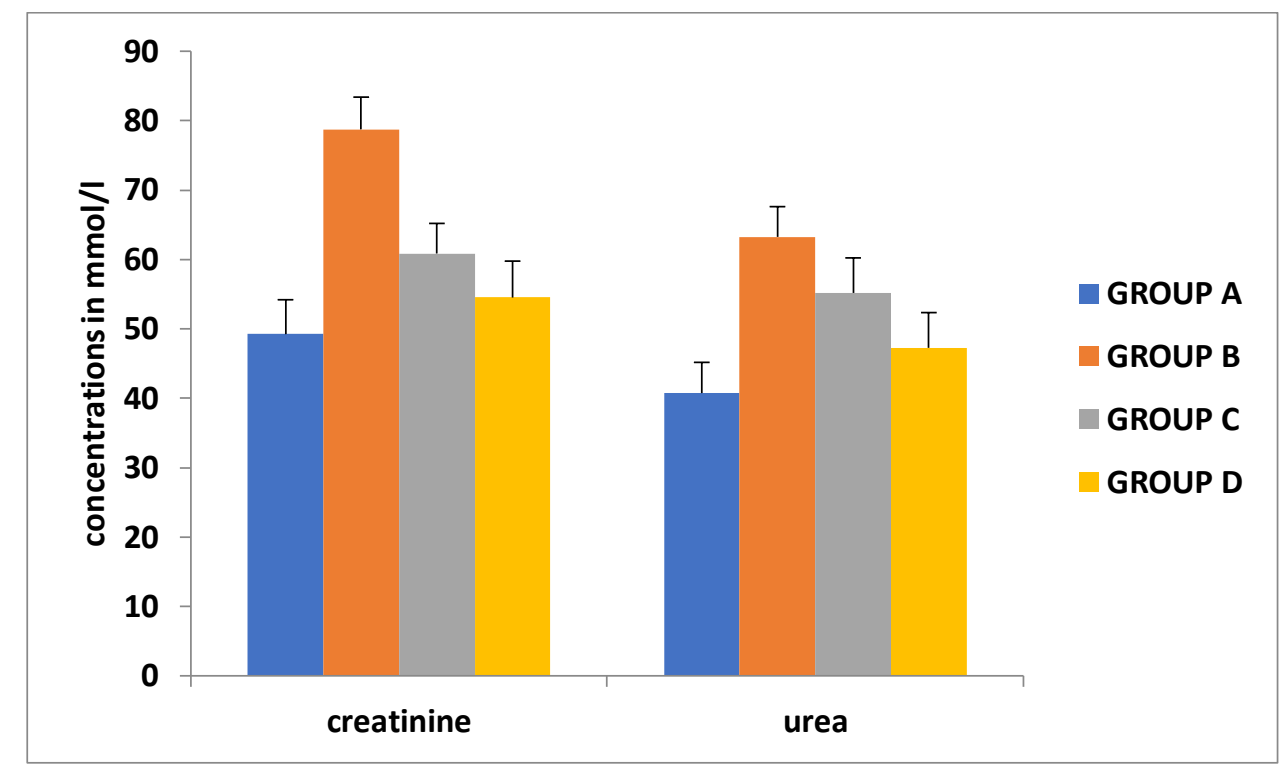

Figure 4: Creatinine and urea concentration in the kidney of cadmium-intoxicated rats treated with Annona nuricata seed extract

Key: $\mathrm{A}=$ Control. $\mathrm{B}=\mathrm{Cd}$ only. $\mathrm{C}=\mathrm{Cd}+200 \mathrm{mg} / \mathrm{kg}$ bw ESEAM. $\mathrm{D}=\mathrm{Cd}+500 \mathrm{mg} / \mathrm{kg}$ bw ESEAM

\section{DISCUSSION}

Results obtained show a significant increase in body weight and relative brain weight in all the rats in the experimental groups. However, the body weight gained by the rats treated with cadmium alone is decreased as compared with the control. This decrease may be due to the fact that $\mathrm{Cd}$ causes gastrointestinal irritation which may reduce the intestinal absorption of food/nutrients. Treatment with ethanolic seed extract of Annona muricata causes elevation in the body weight and organ weight in rats, thus suggesting that the extract increased appetite and feed efficiency, enhanced nutrient metabolism and utilization while it also decreased nutrient loss (Osmund, 2001; Oyewole and Oladele, 2017).

This study also shows that administration of cadmium chloride in rats resulted in significant
$(\mathrm{P}<0.05)$ increased in MDA level, an end product of lipid peroxidation in the liver. Lipid peroxidation is a degenerative pathway of membrane components which is initiated by the attack of radicals on the double bond of unsaturated fatty acid and arachidonic acid, to generate highly reactive lipid peroxyl radicals that initiate chain reactions that further attacks on another unsaturated fatty acid. The increased lipid peroxidation level observed in this study might be a consequence of increased free radical formation as well as the disruption of antioxidant status. Treatment with ethanolic seed extract of Annona Muricata mitigated against increased MDA showing that ethanolic seed extract of Annona Muricata may protect membrane against free radical attack.

The level of Ascorbic acid and reduced glutathione in the kidney of experimental rats treated with cadmium chloride alone was significantly reduced when 
compared with the control; this implies that oxidative stress was induced following the exposure to cadmium chloride. To further potentiate the induction of oxidative stress by cadmium chloride in this study, catalase (CAT), superoxide dismutase (SOD) and glutathione peroxidase (GPx) activities were found to be significantly reduced in animal treated with cadmium chloride. This result is in tandem with a previous report (Oyewole and Akinbamijo, 2015). However, the administration of ethanolic seed extract of Annona Muricata significantly reversed and ameliorated these alterations confirming the free radical scavenging and antioxidant properties of Annona Muricata.

The serum concentrations of urea and creatinine of rats treated with cadmium were significantly $(\mathrm{p}<0.05)$ increase as compared with control. Urea and creatinine are important indicators of renal function which is routinely measured to assess the kidney health status. The increased level of these renal metabolites (urea and creatinine) in the serum might be due to the inability of the kidney to excrete them out of the circulatory system as a result of impairment in its biochemical and physiological activities (Patil et al., 2007; Oyewole and Oladele, 2016). However, the administration of ethanolic seed extract of Annona Muricata significantly reversed the elevated level back to normal in a dose-dependent manner confirming the renal protective ability of the extract.

\section{CONCLUSION}

The results of this study suggest that ethanolic seed extract of Annona Muricata administration at the tested doses caused a significant increase in body weight and therefore may be suggested to be useful in conditions with a reduction in nutrient metabolism and utilization. The extracts also have antioxidative properties as well as modulatory effects against cadmium-induced renal dysfunction

\section{CONFLICT OF INTEREST}

The authors declare no conflict of interest.

\section{REFERENCES}

Adewole S. and Ojewole J. (2009). Protective effects of Annona muricatalinn. (Annonaceae) leaf aqueous extract on serum lipid profiles and oxidative stress in hepatocytes of streptozotocin-treated diabetic rats. Afr. J Tradit Complement Altern Med.; 6:30-41.

Adewole SO, Caxton-Martins EA. (2006). Morphological changes and hypoglycemic effects of Annona muricata Linn. (Annonaceae) leaf aqueous extract on pancreatic B-cells of streptozotocin-treated diabetic rats. Afr. J Biomed Res. 9:173-187.

Cheesbrough M. (2005). Measurement of serum or plasma creatinine and urea. In, District laboratory practice in tropical countries. 2nd Edition. Cambridge University Press, pp 333340.

De Souza R., Benassi E., da Silva R.R., Afonso S. and Scarminio I.S. (2009). Enhanced extraction yields and mobile phase separations by solvent mixtures for the analysis of metabolites in Annona muricataL. Leaves. J Sep Sci.; 32:4176-4185.

Jagota S.K. and Dani H.M.A. (1982). New colorimetric technique for the estimation of vitamin C using Folin phenol reagent. Analytical Biochemistry. 127. 178-182.

Jollow D.J., Michel J.R., Zam N. and Gillette J.R. (1974). Necrosis protective role of gluthatthione and evidence for 3,4bromobenzene oxide as a hepatotoxic metabolite. Pharmacol.11: 151-169.

Mishra S., Ahmad S., Kumar N. and Sharma B.K. (2013). Annona muricata (the cancer killer): A review. Glob. J. Pharm. Res.2:1613-1618.

Misra H.P. and Fridovich I. (1972). The role of superoxideanion in the auto-oxidation of epinephrine and a simple assayfor superoxide dismutase. J. Biol. Chem. 247:3170-3175.

Moghadamtousi S.Z., Kamarudin M.N.A., Chan C.K., Goh B.H. and Kadir H.A. (2014). Phytochemistry and biology of Loranthus parasiticus merr, a commonly used herbal medicine. Am. J. Chin. Med.42:23-35. 
National Research Council NRC. (2011). Guide for the care and use of laboratory animals 8th Edition. The National Academies Press.

Nogawa, K., Kobayashi, E., Okubo, Y., Suwazono, Y. (2004). Environmental cadmium exposure, adverse effects and preventive measures in Japan. Biometals. 17(5):581-587.

Osmund CE. (2001). Basic Biochemistry of Food Nutrients (1st edn). Immaculate Publication: Enugu, Nigeria.

Oyewole O.I. and Akinbamijo T.O. (2015). Antioxidative potential of Ageratum conyzoides and Zanthoxylum zanthoxyloides extracts in cadmium-induced oxidative stress in rat tissues. American Journal of Biomedical Research. 3(4): 71-74.

Oyewole O.I. and Oladele J.O. (2016). Assessment of cardiac and renal functions in wistar albino rats administered carmoisine and tartrazine. Advances in Biochemistry. 4(3): 21-25.

Oyewole O.I. and Oladele J.O. (2017). Changes in activities of tissues enzymes in rats administered Ficusexasperata leaf extract. Int. J. Biol. Chem. Sci. 11, 378-386.

Oyewole O.I., Shoremi M.O. and Oladele J.O. (2016). Modulatory effects of Ricinus communis leaf extract on cadmium chlorideinduced hyperlipidemia and pancytopenia in rats." American Journal of Biomedical Research, 4 (2):38-41.
Patil A.J., Bhagwat V.R., Patil J.A., Dongre N.N., Ambekar J.G. and Das K.K. (2007). Occupational lead exposure in battery manufacturing workers, silver jewelry workers and spray painters in Western Maharashtra (India): effects on liver and kidney function. J. Basic Clin. Physiol. Pharmacol., 18: 87-100.

Rotruck J.T., Pope A.L., Ganther H.E., Swanson A.B. and Hafeman D.G. (1973). Selenium: biochemical role as a component of glutathione peroxidase. Science. 179: 588-590.

Sinha A.K. (1972). Colorimetric assay of catalase. Analytical Biochemistry. 47: 389-394.

Sorahan T. and Lancashire R.J. (1997). Lung cancer mortality in a cohort of workers employed at a cadmium recovery plant in the United States: an analysis with detailed job histories. Occupational and Environmental Medicine. 54: 194-201.

Varshney R. and Kale R.K. (1990). Effect of calmodulin antagonists on radiation induced lipid peroxidation in microsomes. Int. J. Radiat. Biol. 58: 733-743.

Wu F.E., Gu Z.M., Zeng L., Zhao G.X., Zhang Y., McLaughlin J.L. and Sastrodihardjo S. (1995). Two new cytotoxic monotetra hydrofuran annonaceous acetogenins, annomuricins a and b, from the leaves of Annona muricata. J. Nat. Prod.58:830-836. 